[Thornley, C., Read, K., \& Eason, V. (2001). The Dinosaurs Died a Long Time Ago: A Story from English in the New Zealand Curriculum. New Zealand Annual Review of Education, 10, 125-140]

\section{The Dinosaurs Died a Long Time Ago: A Story from English in the New Zealand Curriculum}

\author{
CHRISTINA THORNLEY, KARON READ AND VIVIENNE \\ EASON
}

\section{Abstract:}

It is now six years since English in the New Zealand Curriculum (Ministry of Education, 1994) was mandated as curriculum policy for New Zealand classrooms. While the debate that surrounded the introduction of achievement levels for language learning in this national curriculum statement appears to have abated, it is essential that teachers continue to discuss the implications of the levels for literacy programmes. This paper describes a research case study undertaken in two Year One classrooms where the children's work in exploring language is analysed against the achievement levels, raising concerns related to the possible underestimation of their abilities in literacy learning.

$\mathrm{I}^{\mathrm{n}}$ troduction: Chris

It is now some years since I experienced my first wave of excitement while listening to the five year old children in my class as they discussed literature. As part of a most precious daily ritual, the children were reading their writing to their new entrant classmates. One child Simon, began reading from his book (which I could see had only a " $d$ " written on the page). He read:

"The dinosaurs died a long time ago."

Then members of the literary audience raised their hands knowing that this was their opportunity to ask the author a question. Simon chose his friend Tommy.

"Yes Tommy?"

"Am I going to be in this story?"
"No you can't be. You see it's non-fiction about dinosaurs".

"Oh! (pause) Well why did all the dinosaurs die?"

As the teacher listening, I was immediately aware that this conversation was occurring irrespective of my participation. Those engaged in it were serious and sincere in their exploration of this written text. They demonstrated their knowledge and understanding, but most impressively, they demonstrated their ownership of this exploring language process. As I frequently revisit this scenario, I continue to grapple with the questions of how such behaviour is supported by English in the New Zealand Curriculum (Ministry of Education, 1994), and more importantly whether we as teachers can foster such conversations, the ones that I believe verify our success in developing life-long readers.

\section{The Research: Chris, Karon, and Viv}

In talking with Karon and Viv (both new entrant teachers), about our classroom experiences, we discovered a shared concern relating to people's perceptions of children in junior classes. We believed that five year olds were often underestimated by those who did not work closely with them. Many people only saw the obvious things like their size and unfamiliarity with the bewildering world of schools, and equated this with incompetence. Karon and Viv could readily match my story of Simon and Tommy with similar stories of the children from their classes. We worried that English in the New Zealand Curriculum did not necessarily reflect our expectations for the five year olds with whom we had worked. We believed that the curriculum had to be presented in such a way that it did not restrict children but encouraged them to be active, involved and able to initiate their own learning. It appeared to us that the purposeful usage of "general language" in the curriculum (Ministry of Education, 1999) could be used either positively or negatively to support young children's learning.

The decision was made to work together, studying children's learning in one aspect of the English curriculum. We wanted to look at the knowledge that young children could acquire and the manner in which they could apply it as part of the regular classroom reading programme. There were two reasons why the exploring language strand seemed perfect for this purpose. The first reason was that exploring language had been a recent addition to the curriculum for five year olds. As such, this strand was supported by meagre research information in the New Zealand setting, where emergent and early literacy discussions continued to be focused on the merits of phonics and whole language 
pedagogies. The second reason was that the stated purpose of the exploring language strand of the reading programme appeared to meet our goals.

Knowledge about language is an area of intrinsic interest, worthy of attention in its own right. It is important for students' language development. Such knowledge, expressed in relevant terminology, enables students to talk about texts in an informed way. All students must learn the conventions of formal English. Learning how to make knowledge of language explicit provides a basis from which they can make informed and conscious choices of language. (Ministry of Education, 1994, p. 17)

Our intention was to introduce the relevant terminology to describe the conventions of fiction and non-fiction through the classroom reading and writing programmes. The study would then focus on the manner in which the children would use this terminology to talk in an informed way about the choices that they made as readers and writers. This decision was motivated by our acknowledgment of the importance of factual writing in people's lives (Furniss \& Green, 1991), and a desire to encourage children to engage with this from the outset. While some research findings indicated children's preferences for fiction (Biddulph \& Biddulph, 1999), we hoped that this project would foster an interest in non-fiction texts through the study of their language features and conventions. We wanted a concept with which they could readily identify and subsequently create conversations in the contexts of their own reading and writing experiences. This topic was further deemed appropriate given the propensity of children of this age to conceive much of their world in the context of binary opposites (Egan, 1997).While we understood that a world view based upon binaries, e.g., hot/cold, good/evil, happy/sad, promotes a simplistic interpretation of a complex reality, the notions of fiction and non-fiction are an accepted division for much of the literature that these young children encounter.

\section{The Background: New Pathways for Novice Readers}

Junior school reading programmes in New Zealand have been guided by the syllabi for instruction in English, since 1878. Throughout the intervening years they have reflected a view of reading as a task to be undertaken in the primary school. As five year olds begin their schooling, the focus is immediately directed to their progress and achievement in reading (Clay, 1991; Smith \& Elley, 1997; Thornley 1996). The urgency to develop the basic reading decoding and comprehension skills of five year olds may be attributed to the nature of school experiences in this country as a series of predominantly print orientated activities. Curriculum developers, teachers and the wider community have long recognised the importance of reading in schools as the means by which students would access learning in mathematics, science, social studies, and other curriculum areas.

The general inadequacy resulting from poor reading begins to show itself quite early in the child's life. If a child reads poorly, he learns

few new words, he is uncertain of spelling, and meets only a limited

range. (Department of Education, 1953, p. 1)

In a departure from previous curriculum formats, the current curriculum statement, English in the New Zealand Curriculum included reading as a subject for instruction beyond the years of primary schooling. It identified objectives for teaching throughout the entire compulsory schooling sector. The structure aimed at depicting a progression of achievement across eight levels. Therefore it necessitated the development and inclusion of elements of reading instruction beyond basic decoding and comprehension for even the youngest school students and other novice readers. This curriculum included for these students: the ability to use the cue systems; to gain and respond to meaning while drawing on personal background knowledge; to explore the choices made by authors; to identify common conventions of text and writing; and to identify and retrieve information (Ministry of Education, 1994). These objectives are grouped into two sections as functions or purposes (personal and close reading) of reading and as the processes (exploring language, thinking critically and processing information) or "skills that students need to achieve the functions" (Ministry of Education, 1999).

By way of contrast, the reading section of the previous syllabus had included a statement about the attributes of a good reader, describing someone who "enjoys reading and can interpret and assess what he reads ... distinguishing between fact and opinion and detecting a writer's intention and tone" (Department of Education, 1961, p. 3). But for novice or young readers the focus tended to be more on the enjoyment of books, their meaning, the knowledge of print conventions and the development of competency over the reading process. The conversation in which Simon and Tommy engaged appeared to justify the inclusion of the new objectives that would recognise their ability to understand the conventions of text, explore the choices made by authors and understand how they relate to the topic. 


\section{The Objectives Model of Curriculum: Challenge or Support?}

English in the New Zealand Curriculum was written as the third in the series of new national curriculum statements. It followed a predetermined structure, depicting a hierarchical model of teaching and learning based upon the establishment of "clear achievement standards for all levels of compulsory schooling "(Ministry of Education, 1999, p. 1). From the outset there were difficulties identified by the curriculum writers as they grappled with the task of representing a language curriculum with levels depicting a progression of achievement.

Lastly and crucially there was the issue of the eight levels. There is no debate about the inadequacy of that model for an English Language curriculum statement. Suffice it to say that the developers never accepted that there were eight levels waiting to be found. (Bendall, 1994, p. 8)

The linear progressive objectives model was the subject of extensive debate in this area. Bendall's problem exemplified Elley's (1994) concern when reviewing the draft syllabus. He considered that the linear progression would be unable to represent progression in parts of the curriculum where development may be dependent upon the contexts within which children work rather than the task. He illustrated his point as follows:

Indeed, if we were to examine the real difference between a typical

level three child (about nine or ten years old), and a level seven child

(about fifteen years) in reading or listening, it would not be found in such skills as the ability to identify main ideas, or to detect purposes,

or to think critically, so much as the ability to understand

progressively more difficult texts. (Elley, 1994, p. 41)

This was not a new argument. Stenhouse (1976) had critiqued the pre-determined objectives model as inappropriate for use in a humanities curriculum, stating that it was incompatible with the nature of knowledge and education. His illustration of a new entrant class discussing the origins of a playground altercation, as being involved in a task essentially the same as a sixth form history class, provides us with the same argument. Egan (1997) argued the fallacy of "schooling as a progression" claiming that while gains are made in literate understanding through formal schooling, young children also experience significant losses in their abilities as they are moulded to the adult view. His alternative curriculum structure challenged curriculum developers to look beyond a simple acceptance of this fact in order to maintain their notion of progression.

Locke $(1996,1997)$ extended the ideas of these writers, within a specifically New Zealand setting. In response to the final English curriculum statement, he foresaw two possible consequences of the curriculum document's adoption of the linear model; the first being "the potential for dumbing down" and the second "an impasse in assessment"(Locke, 1997, p. 4). He considered that primary teachers who worked diligently from the curriculum would not plan learning activities for their children that required higher level thinking skills, but would work from those included for students of levels one to four. Further he questioned the validity of assessment information and the value of providing parents with achievement information that reflected artificially constructed levels.

\section{Achievement Expectations For Five Year Old Readers}

The outcome of these criticisms was that the reading process objectives were depicted in broader bands to cover two levels or four years of schooling. This was in recognition of the fact that the changes were gradual. However if Locke's thesis were correct, then the curriculum may in fact not support the work of children like Tommy and Simon. Their ability in exploring language had, it appeared, been underestimated through a curriculum structure that implied that their achievements should be more modest than those of older students, particularly those in secondary schools. The commitment to progression within the achievement levels had effectively reduced the demands upon new entrant children, to the extent that at level one, they are not required to use appropriate terminology, or describe, discuss, analyse and evaluate writing in relation to the needs of the audience. Simon and Tommy were surely engaged in aspects of this process.

The potential for the uncritical interpretation of the curriculum levels as reasonable indicators for achievement may lead to the underestimation of what novice readers may achieve. Viewed in this way, the levels become restrictive, within a curriculum that may otherwise provide the broad scope of learning possibilities to enhance the literacy development of young children. This is particularly relevant to the processes which even now are seen as simply the means to achieve the functions, and therefore not necessarily subject to the scrutiny of formal assessment (Ministry of Education, 1999). In an environment where teachers are under the pressure of increased 
assessment demands it is unlikely that they will closely examine anything that is seemingly exempt. Some teachers may, as Locke says, work from the levels without an awareness of what this may mean for their young readers. Yet these processes are seen by some researchers as crucial to the development of literate students. For example, Luke and Freebody state that the process of thinking critically is no less important for young or novice readers than their ability to decode a text. Further they state that, "there is no natural or necessary movement from coding to semantic to pragmatic to critical in an age/grade/ programme sequence (Luke \& Freebody, 1997, p. 220). Five year olds then should be in no way exempt from exposure to the discussion analysis and interpretation of conventions and structures that support their understandings of the meanings and purpose of their texts.

\section{The Research: Conversations for Learning}

Teachers of junior classes frequently initiate exploring language discussions from the texts used for the children's guided and shared reading. The selection of these books is made after an analysis of the children's performance in the running record and other assessments.

The teacher selects a text that is interesting, appropriate in length, and at a level which provides manageable challenges and enough support to facilitate new learning for the majority of the group. (Ministry of Education, 1996, p. 87)

Publishers have commonly organised their children's texts to provide a variety of genres at each level, so that it is not unusual for a five year old to read sequentially from a vast range of text forms, non-fiction and fiction. Teachers' decisions pertaining to exploring language discussions are then based upon the selections of text for purposes other than the commonality of structure or conventions. Applebee (1996) describes this as a catalogue structure for curriculum where there are no overt connections between reading discussions. Children are less able to engage in exploring language discussions because each session focuses on new and unrelated learning, often promoted through new teacher questions initiated by the text.

An alternative model of curriculum organisation, presented by Applebee, facilitates a "stronger sense of topic". He describes an approach where the conversation is focused around ongoing questions that are sufficiently general to be revisited as broad themes or ideas. He considers the strength of this approach is that it allows children to become active in their knowledge-making, as they contemplate the same question in a variety of situations or in a range of contexts. These questions, whether initiated by teachers or students, form the foundation of ongoing conversations and engage students in a process of continuing re-construal of knowledge and meaning. This is not controlled by the teacher alone but by the children, who become active participants in the construction of new learning, appreciating that their own knowledge and ideas are worthy of study.

While the research project was situated within the class programme, Applebee's model, where the curriculum is studied through conversation, was utilised in the learning activities. To this end the children were encouraged by their teachers to apply some broad exploring language questions to the texts that they read. The questions had to be designed in such a manner that they would facilitate ongoing discussion irrespective of the selected texts. For example, "Do you think that this is fiction or non-fiction?", "Could this really happen?", and "Why has the author chosen to show the subject in this way?" Applebee contends that when conversations between teachers and children focus on such broad questions across a number of texts, they are likely to apply their understandings and knowledge to their independent and peer reading experiences. Further, Applebee claims that after teacher modelling, children will develop their own questions for more extensive conversation resulting in the development of "richly contextualised knowledge-in-action" (Applebee, 1996, p. 76).

\section{The Programme}

Karon and Viv had previously introduced the concepts of fiction and non-fiction to the children as they selected their library books. In explaining the layout of the library, these teachers used the correct terminology and described the topics that could be found under the Dewey system. As each new book was introduced, they discussed its possible classification. Library sessions were highly interactive with a strong focus on book selection and reader decision-making. This work formed a strong foundation for that which was to follow.

The books selected by the teachers for each child's guided and shared reading were determined by assessments of their ability to decode and gain meaning from the text. New book purchases for class reading material became influenced by the need for clear examples of non-fiction and fiction. Within the reading programme, some specific lessons were taken on the portrayal of subjects within texts, particularly those that children would recognise in literature as fiction or 
non-fiction. For example, they discussed the beings and objects that are written about as being able to fly, and these were categorised as those born to fly, those made to fly and those that cannot be seen flying. Then these categories were related to the ideas of fiction and non-fiction. A further lesson was taken on the topic of cats and the ways in which they could be portrayed in fiction or non-fiction. The children were then encouraged to make decisions as authors and try some writing about cats themselves.

As writers, the children were generally given some choice about the content and structure of their work, and at home many continued their writing, which they brought to school to read to their teachers and peers. The teachers gave feedback on the surface features and content of all of this writing. As the children developed an increased awareness of the conventions of writing that featured in the different book types, they used writing opportunities to explore the design and usage of contents pages and indexes, the layout of books, the place of illustrations or photographs and other conventions of writing. A series of teaching sessions related to the writing of a non-fiction book about "safe-walking" was planned and implemented. Together the teachers and children worked through the booklet, page by page, exploring the usage of non-fiction conventions. This, of course, was dependent upon the availability and purchase of suitable texts to promote these conversations. The question was then able to be asked "How do you know that this text is non-fiction?"

\section{The Interviews}

In the classrooms, significant conversations were established on two fronts. There were those conversations that were readily developed in response to the questions modelled by the teachers: "Is the text fiction or non-fiction?" and "How do you know this?" There were also conversations initiated naturally from the children's own interests, as Applebee (1996) had suggested, yet still aligned to the class programme. These were conversations around their work as readers and writers and as such were dependent upon their vocabulary and metalanguage that allowed their exploration of text content and structure. In the interviews, both of these types of conversations were evident although the transcripts most commonly evolved from the teacher's (T) questions. There were few examples within the interviews of children engaging in natural conversation about their work and this may be attributable to the unfamiliarity of the interview situation. However, the following example of a writers' conversation was the outcome of a group interview where the members were at ease with each other in discussion. A had just read her fiction writing to $\mathbf{T}, \mathbf{H}$ and $\mathbf{S}$. In this work, she had explored the idea of creatures having human characteristics for humour.

T: Do you think that people would think that that was funny?

A: Yes

T: What sort of people would think that that was funny?

A: Like Sarah and Helen

T: Did you read it to them?

A: Oh no

$\mathrm{H}$ : But I heard her read it out to herself

T: What did you think?

$\mathrm{H}$ : It was funny

T: Was it?

S: I couldn't hear her

T: Would it have been funny if it had been non-fiction?

$\mathrm{H}$ : I heard, I can remember that she said "Yum yum"

A: The worm just said one "Yum"

T: When did it say that?

A: Right at the end

T: And do worms talk?

A: No

A, $\mathrm{H}$, and $\mathrm{S}$ all laugh

T: So why did you put that there?

$\mathrm{H}$ : It's fiction!

The interviews revealed that the children could identify texts as fiction or non-fiction when using their readers or class library books. They could justify their responses appropriately giving reasons of content, structure and the use of conventions. Some of the children also had an understanding of the manner in which text conventions could support the reader. The purchase of suitable texts for school reading had been a major factor in allowing novice readers to access such ideas. In the book discussed below, the contents page was fully illustrated to provide visual assistance for this process.

$\mathrm{T}$ : What have you found in your book? What's this?

W: A contents page

$\mathrm{T}$ : What do they have a contents page for?

$\mathrm{W}$ : To go to the page what you want.

T: Can you do that? How does it work? 
W: You read what you want to learn about and then the wee numbers tell you which page if you are on the right page.

While not all of the children used specific language during the interviews to describe the textual features in their own writing, anecdotal evidence from the classroom writing programme indicated a much higher level of usage was evident in their general conversation. This was supported by many writing samples that demonstrated their exploration of glossaries, contents pages and index numbering.

The notion of making decisions as authors about content became very important as the children developed their understandings of the conventions of fiction and non-fiction. In the interviews, the children eagerly talked about the content of their writing and whether the subjects that they covered were portrayed as fiction or non-fiction. The recognition that they could write to inform about subjects that they had knowledge about seemed very appealing and the opportunity to include the conventions of non-fiction to inform was popular. However, for some children, the use of the conventions may be an obstacle to the recording of their ideas, as described in this example:

$\mathrm{T}$ : When you write do you put in a contents page?

D: Yep

W: No I don't.

D: It's much more easier

F: And then you can go to the page you want to, it's easy-peasy

T: So why don't you put in contents pages?

$\mathrm{W}$ : It takes too long!

This attitude was also reflected by a child who discussed reading a complex library book about space. He was adamant that he would not bother trying to use the contents page - he would just look through for the pictures, the contents page in this case being print only. Again this indicated the importance of books with effective visual information to support the printed text of glossaries and contents pages, rather than just the factual information or story-line. Such books would support novice print decoders as they gain meaning through their knowledge of exploring language conventions.

The use of fiction to entertain was understood by some children. One child in particular wrote and drew about a cat that liked to catch birds and this was, of course, supported by an illustration of a flying cat with wings. Others in their interviews revealed that while they preferred writing or reading about animals in non-fiction, they did know how the same subject could be portrayed fictitiously. Examples of this understanding were evident in the following comments from the interviews "a squirrel could swim under water" or "a tarantula could have long claws".

As the children became more confident in their conversations about how they chose to portray objects, the notions of purpose and audience were introduced by the teachers. At the time of the interviews this aspect of the objectives had been addressed on only a few occasions.

T: Why did you decide to write that?

S: Because I liked my pois

T: Who did you write it for?

S: My family when that book's finished.

$\mathrm{T}$ :Is it going to have other things in it?

$\mathrm{H}$ : And I'd love it!

T: What does it tell people about?

S: It tells, I told, I told in my book how you make pois!

However, the prospect of using humour to entertain their classmates was eagerly embraced by many of the children, as the following example shows.

T: What sort of things have you been writing?

A: I wroted about a worm eating a car called Timothy.

$\mathrm{T}$ : Was that a fiction or a non-fiction one?

A: Fiction.

$\mathrm{T}$ : Why was it a fiction one?

A: Because worms don't eat cars

T: Why did you write that?

A: Because I wanted to write a funny story

The decisions that the children made as authors were not always to support the reader, as in the following instance:

$\mathrm{T}$ : Do you like writing fiction or non-fiction?

$\mathrm{N}$ : Sort of both.

$\mathrm{T}$ : Which is easier?

N: Non-fiction

T Why is it easier?

$\mathrm{N}$ : Because at our house we've got so much non-fiction things, we've got rugby, we've got soccer, and we've got posters and aeroplanes.

The children's ability to discuss the decisions about audience and purpose made by the authors who wrote their class readers or library 
books was more limited. They often explained that these texts were simply written for them to read at school and to enjoy.

M: I've got a non-fiction book.

T: How do you know you've got a non-fiction book?

M: Cos someone has tooken a photo of a lamb and a sheep.

T: Okay, I wonder why they've put a photo of a lamb and a sheep on it.

M: Because its all about sheep.

T: Who do you think they wrote that for?

M: For reading and having fun.

These seemed to be reasonable responses to an enjoyable school reading programme. However, they also highlighted the scope of the classroom programme where junior reading predominantly was based on book texts rather than texts of advertising, newspaper, school newsletters, signs or with other genres. The notion of purpose and audience would need to be explored within these wider contexts.

\section{Conclusion}

These transcripts indicated that the children's work could not be confined within the boundaries outlined for levels 1 and 2 of the exploring language strand. For example, the children used and discussed the writing conventions and language features of different texts. They understood and applied their knowledge of how conventions could be used to suit a pre-determined purpose, and in some instances discussed the appropriateness of language features for their particular audience. Such outcomes cannot be interpreted to suggest that as children achieve the objectives of these levels they must "move on" in the way that a linear model of progression may imply. Rather it validates the claims of Elley (1994), Bendall (1994), and Locke (1997) that such arbitrarilylevelled content does not reflect the possible development of children. Increased challenges would be located within their own reading and writing practices and the sophistication of the texts that they read. The objectives from levels one to eight can be viewed as providing the scope of possibilities for the development of these reading practices in respect of all readers. The children can continue to explore the concepts using texts from a range of genres, including examples that provide less reader support. Their progress is in this way determined not by the level but by the textual complexity of the work that they read and write (Elley, 1994).

Conceptually, the children were able to understand aspects of the content outlined in the achievement objectives vertically through the levels, rather than simply at the initial level where it may have been expected that they would work. An analysis of the factors that facilitated this development identified the importance of teacher attitude and expectation, the availability of suitable texts and the enthusiasm of children to expand their exploring language understandings. The teachers did not use the levels to restrict the programme possibilities. On the contrary, the programme evolved from the needs and interests of the children. The teachers' expectations that the children would engage with the exploring language process, and that their new learning would intrinsically motivate them, supported the children's achievements. They viewed the levels taken as a whole as a representation of the learning possibilities for beginning readers and writers.

The use of questions for on-going conversations further removed limitations as the children were able to develop their own conversation away from the teachers' direct involvement. It was not possible from the interviews to determine the extent to which these conversations were used, but the children demonstrated ownership over the reading and writing concepts introduced by the interviewer. Further classroombased research studies could be designed to reveal the effectiveness of such conversations for fostering children's independence and their ability to explore language features and conventions away from the direct influence of the teacher.

In exploring language, the texts that are available strongly influence the ways in which children can develop their ideas. The tradition of using basic narratives as beginning reading material has served in the past to restrict those novice readers to a diet of books with limited structures to explore. The recent expansion of texts to include a wider range of book genres has enabled this area of the programme to be developed in support of the curriculum statement. The children in this study illustrated that their ability to decode text was in no way circumscribed by their ability to explore language.

English in the New Zealand Curriculum provides teachers with a range of curriculum possibilities for junior school children. The inclusion of content for all students within the compulsory education sector (years one to thirteen), in each national curriculum statement, presents a more expansive reading curriculum than any other for New Zealand primary schools in the past. The challenge for teachers is to provide children with the opportunities to access knowledge and understandings about text that they can apply to their reading and writing. As young children 
demonstrate their willingness and enthusiasm for literary study, conversation can be utilised to encourage on-going learning and exploration of written language. It must be accepted that in junior classrooms where teachers work closely from the levels, as a linear programme model advocates, children may be denied appropriate learning experiences, and the complexity of literary learning may be overlooked in favour of expediency.

\section{References}

Applebee, A. N. (1996). Curriculum as conversation: Transforming traditions of teaching and learning. Chicago \& London: University of Chicago Press.

Bendall, M. (1994, August). Mapping the territory: A review of principles and practicalities in the development of the draft English in the New Zealand Curriculum. Paper presented at the Dunedin Curriculum Institute Conference.

Biddulph, J., \& Biddulph, F. (1999). The challenge of non-fiction. Teachers and Curriculum, 3, 63-72.

Clay, M. (1991). Becoming literate: The construction of inner control. Auckland: Heinemann.

Department of Education. (1961). Primary School Syllabuses: Reading. Wellington: Department of Education.

Department of Education. (1985). Reading in Junior Classes. Wellington: Learning Media.

Egan, K. (1997). The educated mind: How cognitive tools shape our understanding. Chicago \& London: University of Chicago Press

Elley, W. (1994). Curriculum reform: Forwards or backwards? New Zealand Annual Review of Education, 3, 37-49.

Furniss, E., \& Green, P. (Eds.) (1991). The literary connection: Language and learning across the curriculum. Armadale: Eleanor Curtain Publishing.

Locke, T. (1996, December). Yet again: Why levels won't do. English in Aotearoa, 28-32.

Locke, T. (1997, December). Gaps under the glass: Roads not taken in English. Paper presented to New Zealand Association for Research in Education Conference, Auckland.

Luke, A., \& Peabody, P. (1997). Shaping the social practices of reading. In S. Muspratt, A. Luke, \& P. Freebody (Eds.), Constructing critical literacies (pp. 185-225). Australia: Allen and Unwin.

Ministry of Education. (1994). English in the New Zealand Curriculum. Wellington: Learning Media.

Ministry of Education. (1996). The learner as a reader: Developing reading programmes. Wellington: Learning Media.

Ministry of Education. (1998). English units: Assessing against the curriculum. < http//english.unitecnology.ac.nz, pp. 1-4>

Smith, J., \& Elley, W. (1997). How children learn to read. Auckland: Addison Wesley Longman.

Stenhouse, L. (1975). An introduction to curriculum research and development. London: Heinemann.

Thornley, C. (1996). Formal schooling for five year olds in New Zealand. In E. Hujala (Ed.), Childhood education: International perspectives (pp. 259-272). Oulu: Oulun Yliopistopaino.

\section{The authors}

Christina Thornley is a lecturer in the Bachelor of Teaching degree at the School of Education, University of Otago. As a primary school teacher throughout the first years (until 1997) of the reforms associated with the Achievement Initiative, she has a particular interest in curriculum professional development and the English curriculum. Her research interests also include literacy programmes for young children and the impact of a pre-determined objectives-based curriculum for literacy learning.

Karon Read is Assistant Principal of East Taieri School in Otago. She has worked with five year old children for some years and has developed a strong interest in their literacy learning. She has worked at the University of Otago as a guest lecturer and co-researcher studying the achievement of young children within the English curriculum.

Vivienne Eason is a senior teacher at East Taieri school, team teaching with Karon Read. She also has a keen interest in the literacy development of young children and values the role of teacher as researcher for professional development. Vivienne has also worked as researcher and guest lecturer at the University of Otago and in schools with under-graduate student teachers.

Correspondence on this article should be sent to: < christina.thornley@stonebow.ac.nz> 